\title{
Laparoscopic vs open pancreaticoduodenectomy- An updated meta- analysis of randomized control trials.
}

\author{
Bhavin Vasavada ( $\square$ drbhavin.liversurgeon@gmail.com ) \\ Shalby Hospitals https://orcid.org/0000-0003-0502-6499 \\ Hardik Patel \\ Shalby Hospitals
}

\section{Research Article}

Keywords: Heterogeneity, Random-effects Models, Pancreatic Adenocarcinoma, Operative Time, Surgical Site Infection, Blood Loss

Posted Date: June 24th, 2021

DOI: https://doi.org/10.21203/rs.3.rs-644312/v1

License: (c) (i) This work is licensed under a Creative Commons Attribution 4.0 International License. Read Full License 


\section{Abstract}

Background: There is ongoing debate regarding the usefulness of laparoscopic pancreaticoduodenectomy. This study aimed to analyze all the randomized control trials published including the most recent one.

Material and methods: The study was conducted according to the Preferred Reporting Items for Systematic Reviews and Meta-Analyses (PRISMA) statement and MOOSE guidelines. Heterogeneity was measured using Q tests and I2. The random-effects models were used to summarize the relative risks, odds ratios, and mean differences as appropriate.

Results: 4 RCTs were included consisting of 818 patients. 411 patients were in the laparoscopic group and 407 in the open pancreaticoduodenectomy group. Weighted baseline patient characteristics were similar except more patients with pancreatic adenocarcinoma and more males were there in the open pancreaticoduodenectomy group. There was no difference in-hospital stay, 90 days complications rate, 90 days mortality, R1 resection, postoperative pancreatic fistula, delayed gastric emptying, post pancreatectomy hemorrhage, bile leak between the two groups. Operative time was more in the laparoscopic group. Blood loss [mean difference $-132.12 \mathrm{ml}(-172.60,-91.65)$ ] and surgical site infection [Risk ratio 0.41 (0.17-1.0)] were significantly lesser in laparoscopic group.

Conclusion: There was no benefit in-hospital stay or clinical outcomes after laparoscopic pancreaticoduodenectomy. Blood loss and surgical site infection were lesser in laparoscopic pancreaticoduodenectomy.

\section{Background}

Pancreaticoduodenectomy is the only curative option for pancreatic ductal adenocarcinomas, duodenal carcinoma, ampullary carcinoma, lower common bile duct cholangiocarcinoma, and various periampullary regions. It is still associated with very high morbidity and mortality. [1].

Gagner and Pomp first described laparoscopic pancreaticoduodenectomy in 1994.[2]. There have been many technological advancements since then. Many centers are now performing laparoscopic pancreaticoduodenectomy. However, it remains one of the most technically challenging surgery. [3].

Although some retrospective cohort studies showed benefit in-hospital stay. [4]. Recent Randomized control trials failed to show benefits about the hospital stay. The widely discussed LEOPARD II trial showed more harm than benefit with laparoscopic pancreaticoduodenectomy and raised a debate in the scientific world, regarding the usefulness of laparoscopic pancreaticoduodenectomy. LEOPARD II had to be stopped earlier due to more harm related to laparoscopic pancreaticoduodenectomy. [5]

Ausania et al. [6] published a meta-analysis of randomized control trials which showed no difference in mortality, morbidity, and hospital stay between laparoscopic vs open pancreaticoduodenectomy. However, all the randomized control trials included in that were having a limited number of patients.

Recently Wang et al. [7] published a multicenter open-label randomized control trial with a good sample size which showed laparoscopic pancreaticoduodenectomy was associated with the significantly reduced hospital stay. However, the difference in-hospital stay was just one day.

This study aimed to do an updated meta-analysis of all the randomized control trials including the recently published randomized control trial. [7] to look for the difference in-hospital stay, morbidity, and mortality between laparoscopic and open pancreaticoduodenectomy.

\section{Material And Methods}

This study was conducted according to the PRISMA statement and Moose guidelines. [8, 9]. We conducted a literature search as described by Gossen et al. [10]. Pubmed, Cochrane Library, Embase, Google Scholar, Web of Science with keywords like 'laparoscopic pancreaticoduodenectomy'; 'open pancreaticoduodenectomy'; 'periampullary cancer”; 'Whipple pancreaticoduodenectomy'; 'Pancreatic ductal adenocarcinoma'; 'duodenal carcinoma'. Two independent authors extracted the data (B.V. and H.P.) Discussions and mutual understanding resolved any disagreements.

\section{Statistical analysis:}

The meta-analysis was conducted using Review Manager 5.4. Heterogeneity was measured using $\mathrm{Q}$ tests and I2, and $\mathrm{P}<.10$ was determined as significant, the random-effects model was used. The risk ratios (RR)/odds ratios (OR) were calculated for dichotomous data wherever applied and weighted mean differences (WMD) were used for continuous variables. Both differences were presented with $95 \% \mathrm{Cl}$. For continuous variables, if data were presented with medians and ranges, then we calculated the means and standard deviations according to Hozo et al. [11, 12]. If the study presented the median and interquartile range, the median was treated as the mean, and the interquartile ranges were calculated using 1.35 
SDs, as described in the Cochrane handbook. Assessments of bias were done according to the Cochrane handbook. [11]. Publication bias was assessed using funnel plots. The review was not registered.

Inclusion criteria:

- Randomized control trials

- Trials containing laparoscopic pancreaticoduodenectomy and open pancreaticoduodenectomy

- English language studies

Exclusion criteria:

- Nonrandomized control trials

- Duplicate studies

- Where full text was not available

- Trials that did not mention short term outcomes

- Other languages studies.

\section{Results}

4 randomized control trials $(5,7,16,17)$ consisting of 818 patients were included in the final analysis. [Figure 1]. 411 in the laparoscopic arm and 407 in the open pancreaticoduodenectomy group. Study characteristics are described in Table 1. The risk of bias summary is described in Fig. 2. 
Table 1

Study characteristics.

\begin{tabular}{|c|c|c|c|c|}
\hline & LEOPARD II & PADULAP & PLOT & WANG ET AL. \\
\hline & 2019 (1:1 randomization) & $2018(1: 1)$ & $2017(1: 1)$ & $2021(1: 1)$ \\
\hline \multirow{3}{*}{$\begin{array}{l}\text { NUMBER OF } \\
\text { PARTICIPANTS IN EACH } \\
\text { GROUP }\end{array}$} & Laparoscopic & Laparoscopic: 32, & Laparoscopic: 32, & Laparoscopic: 297, \\
\hline & :50, & Open:29 & Open:32 & Open: 297 \\
\hline & \multicolumn{4}{|l|}{ Open: 49} \\
\hline $\begin{array}{l}\text { TYPE (INTENTIO TO } \\
\text { TREAT/PER PEROTOCOL) }\end{array}$ & Intention to treat & Intention to treat & Intention to treat & Intention to treat \\
\hline PRIMARY OUTCOME & Functional recovery & Length of stay & Length of stay & Length of stay \\
\hline BLINDING & Single & None & None & $\begin{array}{l}\text { None. Surgeons were not } \\
\text { involved in post } \\
\text { operative management }\end{array}$ \\
\hline \multirow[t]{2}{*}{ STUDY POWER } & \multirow{2}{*}{$\begin{array}{l}80 \% \text { for sample size of } 68 \text { in } \\
\text { each group. }\end{array}$} & $80 \%$ & $80 \%$ & $80 \%$ \\
\hline & & Type 1error 0.05 & Type 1 error 0.05 & Type 1 error 0.05 \\
\hline \multirow[t]{2}{*}{ COMPLETED/TERMINATED } & \multirow{2}{*}{$\begin{array}{l}\text { Terminated due to high } \\
\text { complications in } \\
\text { laparoscopic group }\end{array}$} & Completed & Completed & $80 \%$ \\
\hline & & $\begin{array}{l}2 \text { in laparoscopic and } 3 \\
\text { in open group did not } \\
\text { receive intervention }\end{array}$ & & Type 1 error 0.05 \\
\hline $\begin{array}{l}\text { SINGLE } \\
\text { CENTER/MULTICENTER }\end{array}$ & Multicentric & Single centric & Single centric & Multicentric \\
\hline SURGEON'S EXPERIENCE & $\begin{array}{l}\text { Atleast } 20 \text { Laparoscopic } \\
\text { pancreaticoduodenectomy,50 } \\
\text { open } \\
\text { pancreaticoduodenectomy,20 } \\
\text { advanced laparoscopic GI } \\
\text { surgery }\end{array}$ & $\begin{array}{l}\text { Single expert surgeon } \\
\text { each for laparoscopic } \\
\text { and open }\end{array}$ & Two expert surgeons & $\begin{array}{l}\text { (1) performed at least } \\
104 \text { LPD operations and } \\
104 \text { OPD operations;19 } \\
\text { (2) completed the MITG- } \\
\text { P-CPAM LPD training } \\
\text { programme; and (3) } \\
\text { submitted unedited } \\
\text { videos of themselves } \\
\text { doing LPD and OPD } \\
\text { procedures that were } \\
\text { considered as adeptly } \\
\text { done by independent } \\
\text { expert evaluation }\end{array}$ \\
\hline
\end{tabular}




\begin{tabular}{|c|c|c|c|c|}
\hline & $\begin{array}{l}\text { LEOPARD II } \\
2019 \text { (1:1 randomization) }\end{array}$ & $\begin{array}{l}\text { PADULAP } \\
2018(1: 1)\end{array}$ & $\begin{array}{l}\text { PLOT } \\
2017(1: 1)\end{array}$ & $\begin{array}{l}\text { WANG ET AL. } \\
2021(1: 1)\end{array}$ \\
\hline Inclusion criteria & $\begin{array}{l}\text { > } 18 \text { years, benign, } \\
\text { premalignant/malignant }\end{array}$ & $\begin{array}{l}\text { > } 18 \text { years, benign, } \\
\text { premalignant/malignant }\end{array}$ & $\begin{array}{l}\text { Patients of either } \\
\text { sex, aged } 30-70 \\
\text { years, with a } \\
\text { diagnosis } \\
\text { of resectable } \\
\text { periampullary (distal } \\
\text { cholangiocarcinoma, } \\
\text { or } \\
\text { duodenal, ampullary } \\
\text { or pancreatic head) } \\
\text { cancer, } \\
\text { no radiological } \\
\text { involvement } \\
\text { of the superior } \\
\text { mesenteric vein and } \\
\text { portal vein, } \\
\text { and preserved fat } \\
\text { planes between the } \\
\text { tumour and coeliac } \\
\text { axis, hepatic artery } \\
\text { and superior } \\
\text { mesenteric artery. } \\
\text { without previous } \\
\text { chemotherapy } \\
\text { without metastatic } \\
\text { disease }\end{array}$ & $\begin{array}{l}\text { Patients aged 18-75 } \\
\text { years with benign, } \\
\text { premalignant, or } \\
\text { malignant resectable } \\
\text { tumours of the } \\
\text { pancreatic and } \\
\text { periampullary region }\end{array}$ \\
\hline Exclusion Criteria & $\begin{array}{l}\text { Tumor involvement of major } \\
\text { vasculature } \\
(\mathrm{SMV}, \mathrm{PV}, \mathrm{SMA}, \mathrm{HA}), \mathrm{BMI}>35 \\
\mathrm{~kg} / \mathrm{m} 2 \text {, receipt of neoaduvant } \\
\text { therapy }\end{array}$ & $\begin{array}{l}\text { metastatic disease; } \\
\text { locally advanced tumor } \\
\text { requiring } \\
\text { preplanned major } \\
\text { vascular resection; } \\
\text { rescue surgery after } \\
\text { neoadjuvant } \\
\text { treatment; Eastern } \\
\text { Cooperative Oncology } \\
\text { group (ECOG) } \\
\text { score>2; severe chronic } \\
\text { hepatic, renal, } \\
\text { pulmonary, or cardiac } \\
\text { disease; clearly hostile } \\
\text { abdomen for } \\
\text { laparoscopic approach; } \\
\text { pregnancy. } \\
\text { and patient's refusal }\end{array}$ & $\begin{array}{l}\text { unresectable disease } \\
\text { at the outset, } \\
\text { unresectable disease } \\
\text { at a later stage of } \\
\text { the procedure }\end{array}$ & $\begin{array}{l}\text { (1) patients with distant } \\
\text { metastases; (2) patients } \\
\text { who underwent left, } \\
\text { central, or total } \\
\text { pancreatectomy, or } \\
\text { palliative surgery other } \\
\text { than } \\
\text { pancreatoduodenectomy } \\
\text { (3) patients with an } \\
\text { American Society of } \\
\text { Anesthesiologists (ASA) } \\
\text { score of at least 4; (4) } \\
\text { patients with } \\
\text { synchronous malignancy } \\
\text { in other organs or a } \\
\text { second cancer requiring } \\
\text { resection during the } \\
\text { same procedure; (5) } \\
\text { pregnant patients; and } \\
\text { (6) patients who } \\
\text { underwent or required } \\
\text { neoadjuvant } \\
\text { chemoradiotherapy }\end{array}$ \\
\hline Conversion & $N=10(20 \%)$ & $N=8(25 \%)$ & $\mathrm{N}=1(3 \%)$ & $\mathrm{N}=11(3.7 \%)$ \\
\hline
\end{tabular}

We also did a weighted pooled analysis to compare basic characteristics of the patients between laparoscopic pancreaticoduodenectomy and open pancreaticoduodenectomy. [Table 2]. There was a significantly higher number of male patients in the open pancreaticoduodenectomy group $(p=0.005)$, a significantly higher number of patients operated for pancreatic ductal adenocarcinoma in the open pancreaticoduodenectomy group $(p=0.02)$, Tumor size was significantly more in the open pancreaticoduodenectomy group. (Mean difference -2.93$)(p<0.00001)$. 
Table 2

Patients' Characteristics.

\begin{tabular}{|c|c|c|c|c|c|}
\hline Outcome or Subgroup & Studies & Participants & Laparoscopic & Open & $p$ value \\
\hline AMPULLARY (n) & 4 & 818 & 57 & 44 & 0.16 \\
\hline LOWER CBD CHOLANGIO (n) & 4 & 818 & 66 & 63 & 0.79 \\
\hline DUODENAL(n) & 4 & 818 & 71 & 61 & 0.32 \\
\hline Pancreatic Ductal Adenocarcinoma(n) & 4 & 818 & 124 & 153 & 0.02 \\
\hline OTHER HISTOLOGY(n) & 4 & 818 & 92 & 88 & 0.81 \\
\hline ASA $>2$ & 4 & 819 & 97 & 90 & 0.63 \\
\hline SOFT PANCREAS & 3 & 754 & 235 & 202 & 0.08 \\
\hline SIZE OF TUMOR & 3 & 224 & Mean difference - 2.93 & & $<0.00001$ \\
\hline DUCT DIAMETER LESS THAN 3 & 2 & 655 & 200 & 187 & 0.4 \\
\hline AGE & 4 & 818 & & Mean difference 0.15 & 0.81 \\
\hline SEX & 4 & 818 & 222 & 260 & 0.005 \\
\hline
\end{tabular}

Hospital stays(Primary Outcome): (Fig. 3)

There was no significant difference in the hospital stay between laparoscopic and open pancreaticoduodenectomy. [weighted mean difference: $-0.91,95 \%$ confidence interval $(-3.58,1.76), p=0.51]$.

Complication rates and mortality: (Fig. 4)

There was no difference in 90 days mortality between the two groups. $(p=0.93)$.[Figure $4(a)$ ]. There was no difference in Clavien-Dindo garde > = 3. Complication rates between laparoscopic and pancreaticoduodenectomy. $(p=0.8)$. [Figure 4(b)]. There was no significant difference in clinically significant postoperative pancreatic fistula rates, clinically significant delayed gastric emptying clinically significant post pancreatectomy hemorrhage, and bile leak. Surgical site infection was significantly less in laparoscopic pancreaticoduodenectomy. [Risk ratio 0.41 (0.17-1.00), $p=$ 0.05](Table 3) (Supplement Fig. 1). Postoperative pancreatic fistula, postoperative delayed gastric emptying, and post pancreatectomy hemorrhage were defined according to ISGPS (International study group of pancreatic surgery) Definitions. $(13,14,15)$. 
Table 3

Secondary Outcomes.

\begin{tabular}{|c|c|c|c|c|c|}
\hline Outcome or Subgroup & Studies & Participants & Statistical Method & Effect Estimate & p value \\
\hline OPERATIVE TIME & 4 & 810 & $\begin{array}{l}\text { Mean Difference (IV, Random, 95\% } \\
\text { Cl) }\end{array}$ & $70.67[38.51,102.84]$ & $<0.0001$ \\
\hline R1 RESECTION & 4 & 818 & $\begin{array}{l}\text { Odds Ratio (M-H, Random, 95\% } \\
\mathrm{Cl})\end{array}$ & $0.72[0.40,1.31]$ & 0.28 \\
\hline BLOOD LOSS & 3 & 758 & $\begin{array}{l}\text { Mean Difference (IV, Random, 95\% } \\
\mathrm{CI} \text { ) }\end{array}$ & $\begin{array}{l}-132.12[-172.60 \\
-91.65]\end{array}$ & $<.00001$ \\
\hline PANCREATIC FISTULA (B/C) & 4 & 818 & Risk Ratio (M-H, Random, 95\% Cl) & $0.86[0.60,1.23]$ & 0.4 \\
\hline DELAYED GASTRIC EMPTYING & 4 & 818 & Risk Ratio (M-H, Random, 95\% Cl) & $0.95[0.59,1.53]$ & 0.82 \\
\hline $\begin{array}{l}\text { POST PANCREATECTOMY } \\
\text { HAEMORRHAGE }\end{array}$ & 4 & 818 & Risk Ratio (M-H, Random, 95\% Cl) & $0.84[0.54,1.30]$ & 0.43 \\
\hline BILE LEAK & 4 & 818 & Risk Ratio (M-H, Random, 95\% Cl) & $1.20[0.68,2.12]$ & 0.53 \\
\hline SURGICAL SITE INFECTION & 2 & 163 & Risk Ratio (M-H, Random, 95\% Cl) & $0.41[0.17,1.00]$ & 0.05 \\
\hline REOPERATION & 4 & 818 & $\begin{array}{l}\text { Odds Ratio (M-H, Random, 95\% } \\
\mathrm{Cl})\end{array}$ & $0.90[0.39,2.12]$ & 0.82 \\
\hline READMISSION & 4 & 818 & $\begin{array}{l}\text { Odds Ratio (M-H, Random, 95\% } \\
\mathrm{Cl})\end{array}$ & $1.16[0.63,2.12]$ & 0.64 \\
\hline ICU STAY & 2 & 658 & $\begin{array}{l}\text { Mean Difference (IV, Random, 95\% } \\
\mathrm{CI} \text { ) }\end{array}$ & $-1.00[-1.08,-0.92]$ & $<.00001$ \\
\hline LYMPHNODE HARVEST & 4 & 818 & $\begin{array}{l}\text { Mean Difference (IV, Random, 95\% } \\
\mathrm{Cl} \text { ) }\end{array}$ & $-0.39[-1.88,1.09]$ & 0.61 \\
\hline
\end{tabular}

Other parameters: (Table 3) (Supplement Fig. 1)

There was no significant difference in Reoperations, Readmissions, lymph node harvest, and R1 resection between both groups. Blood loss was significantly less in the laparoscopic pancreaticoduodenectomy group [Mean difference - 132.12ml $(-172.60,-91.65)$, p < 0.0001], and operative time was significantly more.[Mean difference: 70.67 minutes $(38.51,102.84), p<0.0001]$. ICU stay was significantly less in the laparoscopic group. [ Mean difference of $-1(-1.08,0.92), p<0.00001]$.

\section{Discussion}

Surgeons are always attracted by technology. Minimal invasive techniques like laparoscopy and robotics have revolutionized many fields of surgery. However, there is an ongoing debate about the feasibility and usefulness of laparoscopic pancreaticoduodenectomy with various observational studies showing conflicting results with some showing increased mortality and morbidity. Whereas some showing lack of benefit in term of hospital stays whereas some showing benefits. $(18,19,20,21,22,23)$.

Our meta-analysis aimed to do an updated meta-analysis of randomized control trials including a recently published meta-analysis by wang et al. (7) which was not included in an earlier meta-analysis published. (6), but randomized control trial published by wang et al was the largest until now. Both PLOT and PADULAP trials $(16,17)$ were single-center analysis and also they had a limited sample size. LEOPARD - $2(5)$ terminated their trial earlier owing to higher mortality in the laparoscopic group but their primary outcome was earlier recovery and that reduced power of the study. In that matter recently published meta-analysis by wang et al.(7) was far better evidence., the issue with the trial by wang et al was that significant crossovers from laparoscopic to open hence the difference in sample size in their intention to treat and per-protocol analysis. All the trials involved expert surgeons.

Out of 4 randomized control trials included in our metanalysis LEOPARD-2 (5) had functional recovery as the primary outcome rest all had a hospital stay as the primary outcome. However, LEOPARD-2 mentioned hospital stay separately. There was no significant difference in hospital stay between laparoscopic and open pancreaticoduodenectomy in the meta-analysis. This was an important finding as PLOT, PADULAP and the largest trial by wang et al showed that hospital stay was significantly less in laparoscopic pancreaticoduodenectomy, only LEOPARD-2 showed no difference. However, wang et al showed just a 1-day difference. but weighted meta-analysis showed no difference in hospital stay between laparoscopic and open pancreaticoduodenectomy. ICU stay was significantly less in the laparoscopic group, but the difference was just half to one day. 
There was no difference in mortality, total complications, clinically significant pancreatic fistula, delayed gastric emptying, post pancreatectomy hemorrhage, and bile leak between laparoscopic and open pancreaticoduodenectomy group in our meta-analysis.

Surgical site infections were lesser in the pancreaticoduodenectomy group but due to wider confidence intervals and borderline significance, the quality of this evidence can be termed low. Blood loss was significantly less in the laparoscopic group but in the pooled analysis of patients' characteristics, open pancreaticoduodenectomy had larger size tumors, more male patients, and more pancreatic ductal adenocarcinoma and hence pancreatic head tumors, which can be the cause.

There was no significant difference in reoperation, readmissions, R1 resections or lymph node harvest between the group but all the surgeons involved in each trial were very experienced surgeon so real-world implications are remained to be seen. Operative time was significantly high in the laparoscopic group without visible benefits in clinical outcomes as per our metanalysis.

If we evaluate the component of pancreatic fistula risk score (24). Three Studies evaluated pancreas gland structure (754 patients), all four evaluated histology (818 patients), three studied evaluated blood loss (758 patients), two studies duct diameter (655 patients). Blood loss was significantly more in the open pancreaticoduodenectomy group, more patients operated for pancreatic ductal adenocarcinoma in the open pancreaticoduodenectomy group. There was no difference in duct diameter or gland structure. So, despite higher pancreatic fistula risk in the open pancreaticoduodenectomy group still, there was no difference in postoperative pancreatic fistula rates. These findings need to be evaluated in larger studies with pancreatic fistula, complications, mortality as primary outcomes.

The strength of this meta-analysis is that it is an updated metanalysis including the most recent and largest randomized control trial. Publication bias was nonsignificant in Eager's test in every analysis. A limitation is very few randomized control trials available. Heterogeneity was high and significant in-hospital stay, operative time, blood loss, and lymph node harvest. For the other analysis heterogeneity was mild to moderate as per 12 analysis and nonsignificant.

In conclusion, laparoscopic pancreaticoduodenectomy had a little extra benefit over open pancreaticoduodenectomy. There may be slight benefits in surgical site infections, ICU stays and blood loss with low certainty, but it seems there is hardly any benefits in-hospital stay or clinically important outcomes but also it seems it is non-inferior to open pancreaticoduodenectomy concerning mortality, complications, pancreatic fistula rates, delayed gastric emptying and post pancreatectomy hemorrhage.

\section{References}

1. Newhook TE, LaPar DJ, Lindberg JM, Bauer TW, Adams RB, Zaydfudim VM. Morbidity and mortality of pancreaticoduodenectomy for benign and premalignant pancreatic neoplasms. J Gastrointest Surg. 2015;19(6):1072-1077.

2. Gagner M, Pomp A. Laparoscopic pylorus-preserving pancreatoduodenectomy. Surg Endosc. 1994 May;8(5):408-10.

3. Jacobs MJ, Kamyab A. Total laparoscopic pancreaticoduodenectomy. JSLS. 2013 Apr-Jun;17(2):188 - 93.

4. Qin R, Kendrick ML, Wolfgang CL, et al. International expert consensus on laparoscopic pancreaticoduodenectomy. Hepatobiliary Surg Nutr. 2020;9(4):464-483.

5. Laparoscopic versus open pancreatoduodenectomy for pancreatic or periampullary tumours (LEOPARD-2): a multicentre, patient-blinded, randomised controlled phase 2/3 trial. Lancet Gastroenterol Hepatol. 2019;4(3):199-207.

6. Ausania F, Landi F, Martínez-Pérez A, Fondevila C. A meta-analysis of randomized controlled trials comparing laparoscopic vs open pancreaticoduodenectomy. HPB (Oxford). 2019;21(12):1613-1620.

7. Wang M, Li D, Chen R, et al. Laparoscopic versus open pancreatoduodenectomy for pancreatic or periampullary tumours: a multicentre, openlabel, randomised controlled trial [published online ahead of print, 2021 Apr 26]. Lancet Gastroenterol Hepatol. 2021

8. Page MJ, McKenzie JE, Bossuyt PM, et al. The PRISMA 2020 statement: an updated guideline for reporting systematic reviews. BMJ. 2021;372:n71. Published 2021 Mar 29.

9. Stroup DF, Berlin JA, Morton SC, et al. Meta-analysis of observational studies in epidemiology: a proposal for reporting. Meta-analysis of observational studies in epidemiology (MOOSE) group. Jama. 2000; 283(15):2008-2012.

10. Goossen K, Tenckhoff S, Probst P, et al. Optimal literature search for systematic reviews in surgery. Langenbecks Arch Surg. 2018;403(1): 119-129.

11. Higgins JP, Altman DG, Gøtzsche PC, et al. The cochrane collabora- tion's tool for assessing risk of bias in randomised trials. BMJ. 2011; 343:d5928.

12. Hozo SP, Djulbegovic B, Hozo I. Estimating the mean and variance from the median, range, and the size of a sample. BMC Med Res Methodol. 2005;5:13.

13. Bassi C, Marchegiani G, Dervenis C, et al. The 2016 update of the International Study Group (ISGPS) definition and grading of postoperative pancreatic fistula: 11 Years After. Surgery. 2017;161(3):584-591.

Page $8 / 12$ 
14. Wente MN, Bassi C, Dervenis C, et al. Delayed gastric emptying (DGE) after pancreatic surgery: a suggested definition by the International Study Group of Pancreatic Surgery (ISGPS). Surgery. 2007;142(5):761-768.

15. Grützmann R, Rückert F, Hippe-Davies N, Distler M, Saeger HD. Evaluation of the International Study Group of Pancreatic Surgery definition of post-pancreatectomy hemorrhage in a high-volume center. Surgery. 2012;151(4):612-620.

16. Palanivelu C, Senthilnathan P, Sabnis SC, et al. Randomized clinical trial of laparoscopic versus open pancreatoduodenectomy for periampullary tumours. Br J Surg. 2017;104(11):1443-1450.

17. Poves I, Burdío F, Morató O, Iglesias M, Radosevic A, Ilzarbe L, Visa L, Grande L. Comparison of Perioperative Outcomes Between Laparoscopic and Open Approach for Pancreatoduodenectomy: The PADULAP Randomized Controlled Trial. Ann Surg. 2018 Nov;268(5):731-739.

18. Palanivelu C, Jani K, Senthilnathan P, et al. Laparoscopic pancreaticoduodenectomy:technique and outcomes. J Am Coll Surg. 2007;205:222-230.

19. Kendrick ML, Cusati D. Total laparoscopic pancreaticoduodenectomy: feasibility and outcome in an early experience. Arch Surg. 2010;145:19-23.

20. Asbun HJ, Stauffer JA. Laparoscopic vs open pancreaticoduodenectomy: overall outcomes and severity of complications using the Accordion Severity Grading System. J Am Coll Surg. 2012;215:810-819.

21. Hakeem AR, Verbeke CS, Cairns A, et al. A matched-pair analysis of laparoscopic versus open pancreaticoduodenectomy: oncological outcomesusing Leeds Pathology Protocol. Hepatobiliary Pancreat Dis Int. 2014;13: 435-441.

22. Dokmak S, Fte'riche FS, Aussilhou B, et al. Laparoscopic pancreaticoduodenectomy should not be routine for resection of periampullary tumors. J Am Coll Surg. 2015;220:831-838.

23. Adam MA, Choudhury K, Dinan MA, et al. Minimally invasive versus open pancreaticoduodenectomy for cancer: practice patterns and shortterm outcomes among 7061 patients. Ann Surg. 2015;262:372-377.

24. Callery MP, Pratt WB, Kent TS, Chaikof EL, Vollmer CM Jr. A prospectively validated clinical risk score accurately predicts pancreatic fistula after pancreatoduodenectomy. J Am Coll Surg. 2013;216(1):1-14.

\section{Figures}


PRISMA 2020 flow diagram for updated systematic reviews which included searches of databases and registers only

Previous studies

Studies included in previous version of review $(n=3)$

Reports of studies

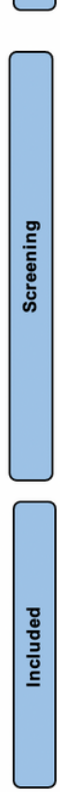

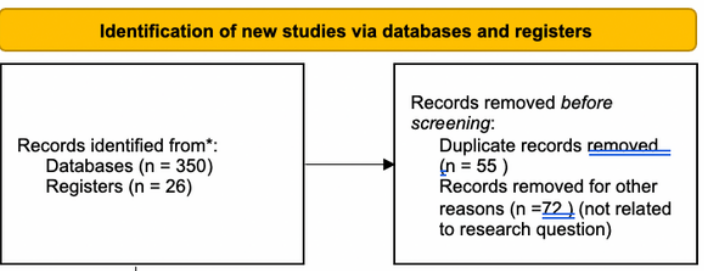

Records excluded*

$(n=173)$ (no comparison group

Records screened

$(n=249)$

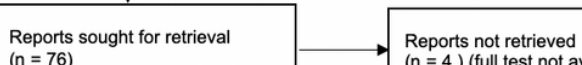

$(\mathrm{n}=\underline{\underline{4}}$ ( full test not available

( $\mathrm{n}=76$ )

Reports assessed for eligibility $(n=72)$
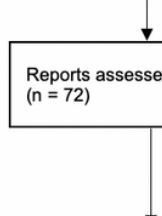

New studies included in review

$$
\begin{aligned}
& \text { New stu } \\
& (n=1)
\end{aligned}
$$

Reports of new included studies

$(n=1)$

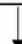

Total studies included in review

$(n=4)$

Reports of total included studies

$(n=4)$

From: Page MJ, McKenzie JE, Bossuyt PM, Boutron I, Hoffmann TC, Mulrow CD, et al. The PRISMA 2020 statement: an updated

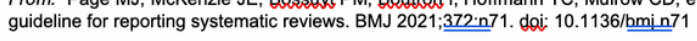

For more information, visit: http://www.prisma-statement.org/

\section{Figure 1}

Prisma flow chart 


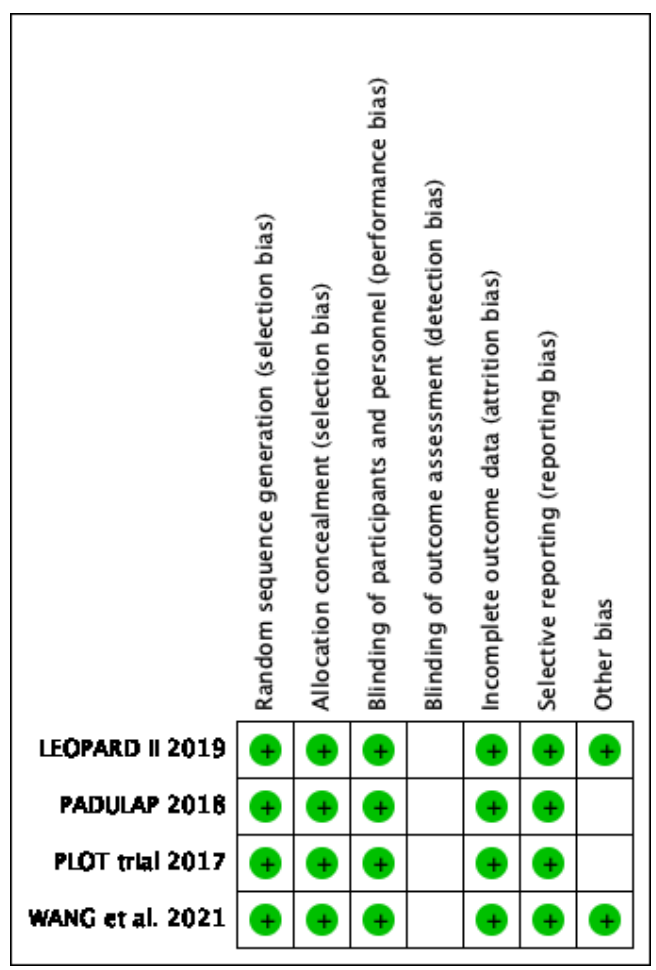

Figure 2

Risk of bias summary, green + denotes low risk of bias, empty square suggests unclear risk.

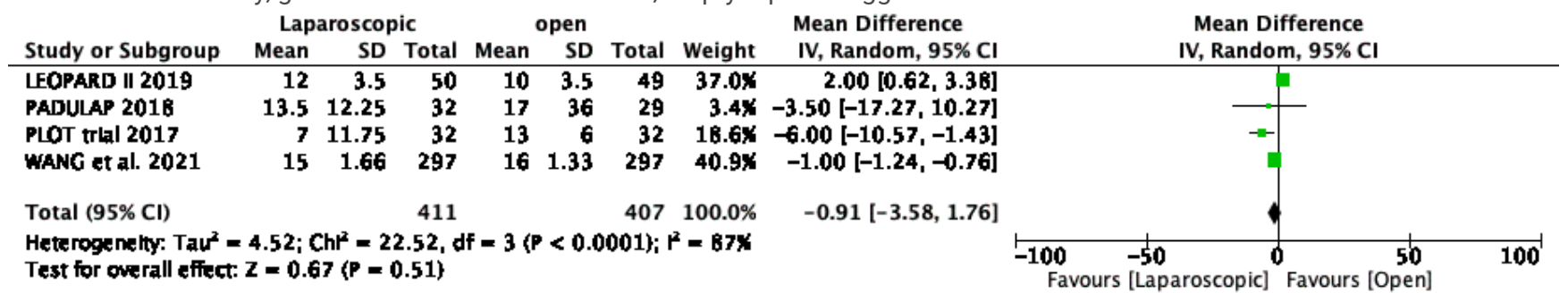

Figure 3

Hospital stays in laparoscopic versus open pancreaticoduodenectomy.

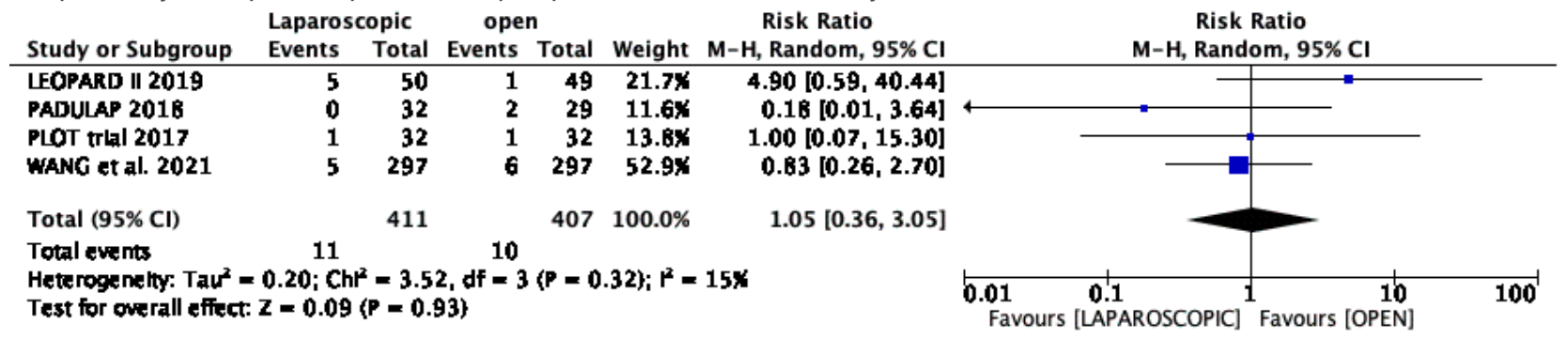

a

Laparoscopic open Risk Ratio Risk Ratio

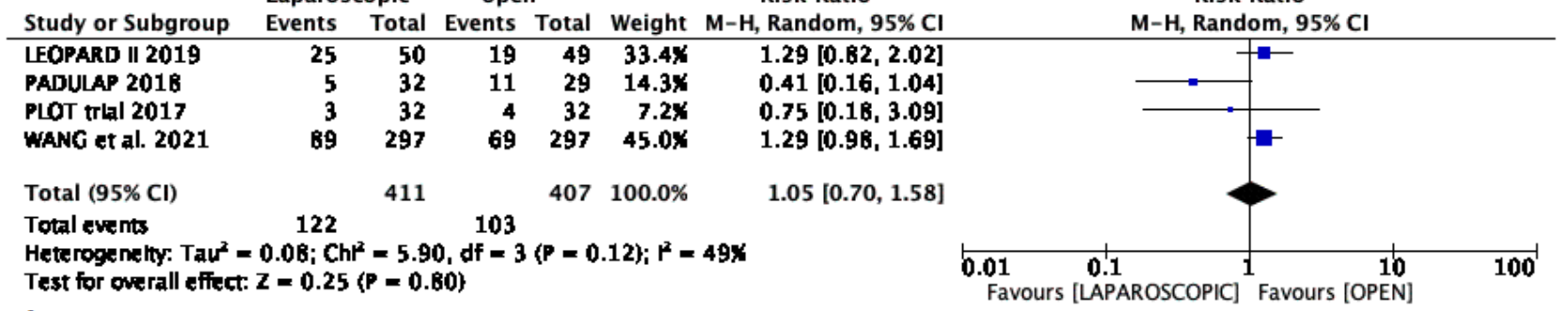

b 
Figure 4

(a) 90 days mortality comparison between laparoscopic and open pancreaticoduodenectomy (b) 90 days morbidity comparison between laparoscopic and open pancreaticoduodenectomy

\section{Supplementary Files}

This is a list of supplementary files associated with this preprint. Click to download.

- SupplementFigure1aOperativetime.png

- Supplementfigure1bR1Resection.png

- SupplementFigure1cBloodloss.png

- Supplement1dPancraticfistula.png

- Supplement1eDelayedgastricemptying.png

- Supplementfigure1fPostpancreatectomyhaemorrhage.png

- SupplementFigure1gBileLeak.png

- SupplementFigure1hSurgicalsitelnfection.png

- SupplemFigure1IReoperation.png

- SupplementFigure1jReadmission.png

- SupplementFigure1kICUStay.png

- SupplementFigure1/Lymphnode.png 